\title{
Impact of the Y-chromosome gene on SOX9 stem cell expression in non-obstructive azoospermic cases
}

\author{
A.K. Saxena ${ }^{1}$, M. Tiwari $^{1}$, R. Kumar ${ }^{1}$, Aprajita ${ }^{1}$, A. Kumar ${ }^{1}$, \\ C.K. Singh ${ }^{1}$ and M. Agarwal ${ }^{2}$ \\ ${ }^{1}$ Human Cytogenetic and Molecular Genetic Laboratory, Department of \\ Pathology and Laboratory Medicine, All India Institute of Medical Sciences, \\ Patna, Bihar, India \\ ${ }^{2}$ Department of Obstetrics \& Gynecology, All India Institute of Medical \\ Sciences, Patna, Bihar, India \\ Corresponding author: A.K. Saxena \\ E-mail: draksaxena1@ rediffmail.com
}

Genet. Mol. Res. 19 (1): gmr18464

Received August 21, 2019

Accepted March 11, 2020

Published March 30, 2020

DOI http://dx.doi.org/10.4238/gmr18464

\begin{abstract}
Sex differentiation in males is a highly complex phenomenon based on synergistic interactions between genes and their coded proteins. The Sox 9 gene plays a critical role in embryonic development, cell lineages, and stem cell maintenance during testicular development. Sox9 gene expression is associated with sex reversal, with a 46, XX karyotype in males and regulating normal functioning of Sertoli cells during spermatogenesis. Clinically diagnosed infertile males $(n=40)$ with non-obstructive azoospermia (NOA) with respective controls $(n=38)$ were included in the study. Blood samples were collected and after isolation of genomic DNA, the expression of the Sox 9 gene (DNA copy number variations) was measured by fluorescence based quantitative PCR, deletion of AZFc locus determined by STS markers, karyotype analysis and SRY using GTG banding and FISH techniques, respectively. Cytogenetics findings revealed that more that $40 \%$ of cases had mosaicism with 46, XY/47, XYY karyotypes and a high frequency of deletion of $\mathrm{AZFc}(>70 \%)$ regions as compared to AZFb (>20\%) using STS markers in the cases of NOA. The mean relative fluorescence values
\end{abstract}


of Sox9 gene expression differed significantly between cases $(0.32)$ and controls $(0.87)(\mathrm{P}<0.001)$ with a confidence interval at $95 \%$ of $0.0310-0.787$ in the cases of NOA. SRY + ve cases had higher Rfv of Sox9 gene expression when compared to SRY- ve cases. There was a positive correlation between stem cell Sox9 gene expression, mosaicism and $\mathrm{AZFc}$ region affecting a non-disjunction event during spermatogenesis and fertility.

Key words: Sox9 gene; SRY; AZFc; Karyotype; Infertility

\section{INTRODUCTION}

Human sex differentiation and determination involve highly complex mechanisms; $\mathrm{Y}$ chromosome genes are responsible for testicular development and spermatogenesis (Berta et al., 1990; Koopman et al., 1991; Foresta et al., 2001). The Sox9 gene plays a critical role during sexual differentiation. The Sox9 gene is mapped on chromosome 17q24.3-q25.1 belongs to the family of Sry related genes and encodes a protein consist of 80 amino acids of HMG domains of DNA binding motif act as a transcription factor (Foster et al., 1994; Grosschedi et al., 1994). The mutation of Sox9 gene causes haploinsufficiency and XY sex reversal with infants requiring genetic analysis due to abnormal external genitalia for confirmation of diagnosis and future management (treatment). Sox9 gene mutation is involved in substitution of either chromosomal translocation or frame shift mutation at nucleotide position $1095 \mathrm{G} \rightarrow \mathrm{AT}$, which alters a $\mathrm{C}$ - terminal transcription factor rich in serine, proline and glutamine residues indicating dominant mode of inheritance (Foster 1996; Sudbeck et al., 1996; Hsiao et al., 2006).

In humans, the most common karyotypic variation either is the translocation between X-Y chromosomes or XXY/XX mosaicism (de la Chapelle et al., 1990) associated with male infertility. The primary role of Sox 9 gene is sex differentiation; in males its expression is up regulated during testicular development but absent in female gonads (Morais da Silva et al., 1996). The Sox9 gene is involved in regulation Sertoli cell - specific expression of anti Mullerian hormone for regression of ducts and male phenotypic development (de Santa Barbara et al., 1998). Sox9 gene copy number variation is responsible for sex reversal in the 46,XX karyotype (Imataka and Arisaka, 2012). We evaluated Sox9 gene expression (DNA CNVs), microdeletion of the Y chromosome, correlations with karyotypic variations and the etiopathology of male infertility.

\section{MATERIAL AND METHODS}

Clinically diagnosed infertile cases with non-obstructive azoospermia (NOA; $\mathrm{n}=$ 40) and aged matched controls $(n=38)$ referred to Department of Pathology/Lab Medicine at All India Institute of Medical Sciences-Patna (AIIMS-Patna) for genetic analysis were included in the study. The study was approved by Institutional Ethical Committee (IEC). Blood samples $(2.0 \mathrm{~mL})$ were collected after written informed consent from the infertile males that were categorized on the basis of semen analysis (WHO, 1992) and couples with one or more children were included as controls. Inclusion criteria were no history of childhood disease, radiation exposure or prescription of continuous drug treatment, and the 
mean age of patients was 35.4 years (age group range 21-45 years). Serum samples were used for hormone profile (testosterone/luteinizing/follicle stimulating hormone) analysis using standard routine laboratory methods (ELISA) with specific antibodies. Genomic DNA was isolated for the study of Sox9 gene expression, microdeletion of Y-chromosome and chromosomal analysis in the cases and controls.

\section{Karyotypes}

Blood samples were collected under sterile conditions and short term lymphocyte cultures were set up for $72 \mathrm{~h}$ at $37^{\circ} \mathrm{C}$, using RPMI 1640 media with 5\% FBS and Phyto - M. Cultures were harvested after addition of colchicine prior $2 \mathrm{~h}$ to arrest the dividing cells at metaphase of the cell- cycle, KCL solution was used as hypotonic and cells were fixed in methanol - acetic acid mixture. The karyotypes were prepared according to the recommendations of the International System for Chromosome Nomenclature (ISCN, 2013) using applied spectral imaging software (Saxena and Kumar, 2019).

\section{Isolation and quantitative analysis of Genomic DNA}

Genomic DNA was extracted according to standard procedures from blood samples according to the manufacturer's recommendations (Promega kit, USA). DNA contents were measured by Nanodrop spectrophotometer (Thermo USA) and stored at $-70^{\circ} \mathrm{C}$ till further analysis.

\section{Microdeletion of Y-chromosome analysis using RT- PCR.}

PCR was performed to analyze the microdeletion in the AZF region of the Y chromosome using specific sequences tagged sites (STS markers Sy254 and Sy267) primers $\mathrm{F}^{5}$ GGG TGT TAC CAG AAG CTT GCA AA R GAA CCG TAT CTA CCA AAG CAG C ${ }^{3}$ and F 5'GAA TGT GTA TTC AAG GAC TTC TCG and R' TAC TTC CCT CGG GGC CTC T 3', respectively of AZFc region. PCR amplification was performed in a $25 \mu \mathrm{L}$ reaction volume containing $10 \mathrm{x}$ Tris $\left(\mathrm{pH} 8.4\right.$ ), $50 \mathrm{mM} \mathrm{KCl,25mM} \mathrm{MgCl}_{2}, 2.5 \mathrm{mM}$ dNTP,10pM of oligonucleotides primers, 50-100 ng DNA and 1U Taq DNA polymerase and PCR condition are $95^{\circ} \mathrm{C}-5 \min \left(94^{\circ} \mathrm{C}-30 \mathrm{~s}, 56^{\circ} \mathrm{C}-45 \mathrm{~s}, 72^{\circ} \mathrm{C}-45 \mathrm{~s}\right) \mathrm{X} 35$ cycles, $72^{\circ} \mathrm{C}-5 \mathrm{~min}$ for SY $254(350 \mathrm{bp})$ and $95^{\circ} \mathrm{C}-50\left(94^{\circ} \mathrm{C}-30 \mathrm{~s}, 56^{\circ} \mathrm{C}-45 \mathrm{~s}, 72^{\circ} \mathrm{C}-45 \mathrm{~s}\right) \mathrm{X} 35$ cycles, $72^{\circ} \mathrm{C}-5 \mathrm{~min}$ for SY $267(102) \mathrm{bp}$, respectively.

\section{SOX9 gene expression using RT PCR based analysis.}

The copy number variation (CNV) of Sox9 gene was analyzed with quantitative PCR using SYBER green as fluorescent dye after selecting two sets of specific primer sequences forward CGGGTGGCTCTAAGGTG, reverse TTGTGCAAGTGCGGGTA (Set A) and forward AGAGGAAGCCGAGTGGT reverse GGCGGGACGGAGATAG (Set B), of 823 bp and $416 \mathrm{bp}$, respectively.

The housekeeping GAPDH was used as a reference internal gene with sequences forward-TGAAGGTCGGAGTCAACGGATTTG and reverse CATGTGGGCCATGAGGTCCACCAC. PCR amplification was performed in a $25 \mu \mathrm{L}$ 
reaction volume containing 10x Tris ( $\mathrm{pH} 8.4$ ), $50 \mathrm{mM} \mathrm{KCl,} 25 \mathrm{mM} \mathrm{MgCl} 2,2.5 \mathrm{mM}$ dNTP, $10 \mathrm{pM}$ of oligonucleotides primers, 50-100 ng DNA and 1U Taq DNA polymerase and PCR condition were $95^{\circ} \mathrm{C}-4 \min \left(95^{\circ} \mathrm{C}-4 \min \left(95^{\circ} \mathrm{C}-30 \mathrm{~s}, 57^{\circ} \mathrm{C}-30 \mathrm{~s}, 72^{\circ} \mathrm{C}-30 \mathrm{~s}\right) \times 40\right.$ cycles, $72^{\circ} \mathrm{C}-8 \mathrm{~min}$. The PCR products (bands) were further analyzed on $1.5 \%$ agarose gel and the bands were visualized on a Gel Doc system (Bio Rad, USA), after ethidium bromide staining.

\section{RESULTS}

The study of Sox9 gene expression (copy number variations) was carried out in the cases of NOA by evaluating RT PCR based relative fluorescence values. The mean $\mathrm{Ct}$ values of Sox9 were 23.76 as compared to GAPDH (18.12) as shown in Figure 1A.
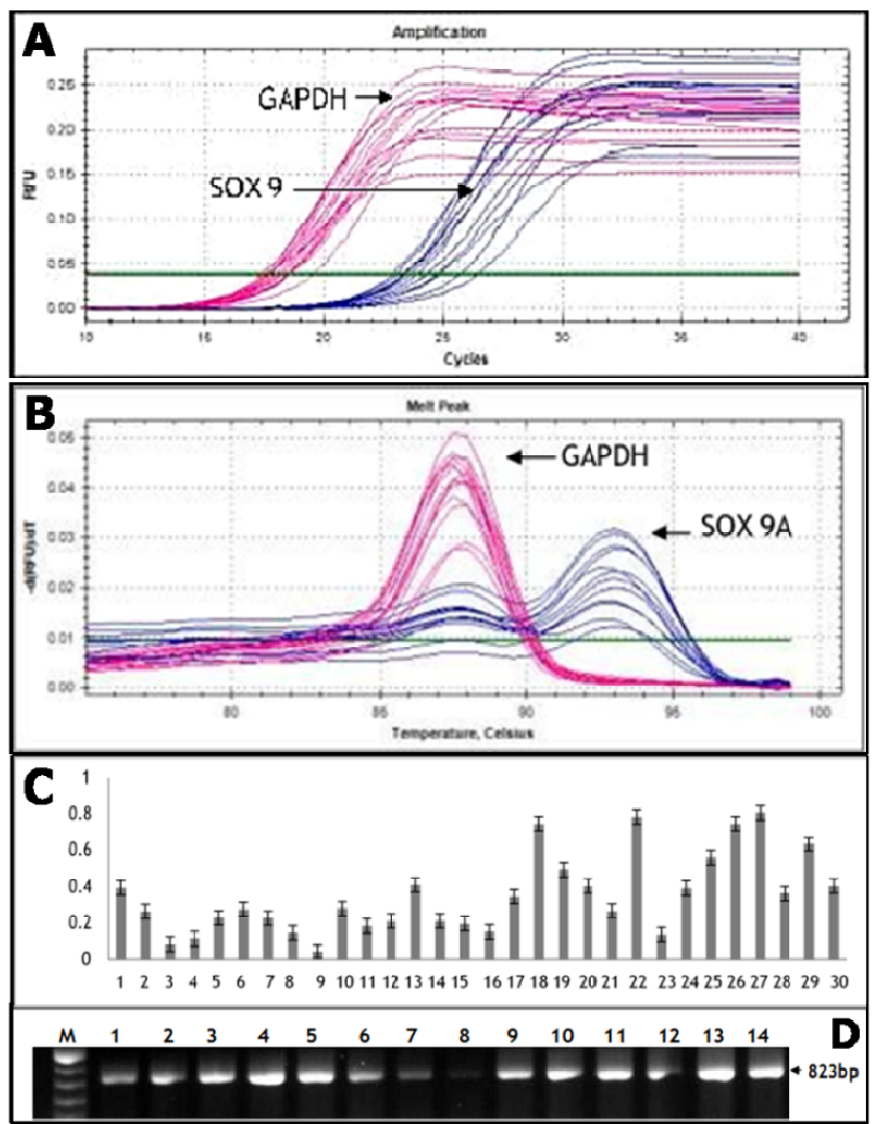

Figure 1. A-D. Concentration of gradient curve and melting curve of fluorescence quantitative PCR in the cases of non-obstructive azoospermia (NOA). Amplification curve represents Sox9 gene expression (arrow mark) and GAPDH gene (arrow mark) (Figure 1A). Melting curve of Sox9 gene represented (arrow), while GAPDH gene used as internal references as shown by arrow in Figure 1B. Bar diagram showing down regulation of stem cell Sox9 gene expression (Lanes $7 \& 8$ ) in terms of relative fluorescence unist (Rfu) in the cases as compared with controls (Figure 1C). The same PCR product was further confirmed by agarose gel electrophoresis (1.5\%) and bands were characterized \& visualized on a Gel Doc System after staining with ethidium bromide as shown in Figure 1D. 
Similarly, the mean $T m$ values of Sox9 were higher at 93.00 when compared to GAPDH (87.50) act as internal reference gene of homeobox region for controls (Figure 1B). Apparently, bar diagram showing that more than $56 \%$ cases have higher expression Sox 9 gene (Figure 1C) as compared to controls. The mean values varied between cases $(0.32)$ of NOA then controls (0.87), and statistical analysis showing a significant difference $(\mathrm{P}<$ 0.001 ) with variation of confidence interval (C.I.) at $95 \% 0.0310-0.787$ using a Student-t test. The same RT PCR products were further analyzed using a 1.5\% agarose gel and intensity of bands were visualized on Gel Doc system after ethidium bromide staining showing differential expression of Sox 9 gene in different cases of NOA. The case numbers 7 and 8 showed down-regulation of Sox 9 gene (arrow mark) as compared to control groups as shown in Figure 1D. The expression of Sox9 gene was also evaluated in the case of SRY (-ve) with 46, XY karyotype, gave a 0.406 value of Rfu and the higher values (0.636) was observed in SRY+ve in the cases on NOA. Interestingly, there was a lack AZFc \& AZFb mutation observed in SRY+ve cases.

The cytogenetic analysis showed a high frequency (>40\%) of mosaicism i.e. 46, $\mathrm{XY} / 47$, XYY observed after karyotyping in the cases of NOA. Besides, the variation of sexchromosome anomalies, autosomal variation was also observed; i.e. one case showing the formation of ring chromosome -13. The findings of microdeletion of euchromatic region of Y-chromosome revealed again a high frequency of mutation $(>60 \%)$ of AZFc locus SY267 and SY350 as compared to AZFb region (>20\%) in the cases of NOA.

\section{DISCUSSION}

Sox 9 gene plays an important role during sex determination in 46, XY individuals. The mutation of Sox 9 gene is responsible for the cases of sex reversal due to increased gene expression and the corresponding protein (Kwok et al., 1995; Jordan et al., 2001). Cytogenetic finding reveals de-novo duplication of Y-chromosomes and to increase mosaicism $(46, \mathrm{XY} / 47, \mathrm{XYY})$. A significant correlation was observed between microdeletion of euchromatic regions of Y-chromosome and mosaicism. More than $15 \%$ of cases of male infertility show an extra copy of Y-chromosomes, leading to variation in karyotypes 47 , XXY (aneuploidy) or 47,XYY chromosomes with different mode of inheritance in the male proband (Robinson and Jacobs, 1999; Athalye et al., 2004; Ross et al., 2012). The Ychromosome and its genes are responsible for normal testicular differentiation, and mutation of its content by either losing or gaining sequences through various actions including recombination mutation, insertion and transposition leading to interference in spermatogenesis (Robinson and Jacobs, 1999; Goncalves et al., 2017). Many studies have documented the frequency of chromosomal aberrations from 16\% in male infertility (Mol et al., 2018; Laan, 2019; Oud et al., 2019), but our study also shows the variations of extra copy of $\mathrm{Y}$ - chromosome leading to develop mosaicism $(46, \mathrm{XY} / 47, \mathrm{XYY})$ in more than $50 \%$ cases. Probably, this occurs due to meiotic non- disjunction event of $X$ chromosome or anaphase lag of chromosome from a normal $46, \mathrm{XY}$ or $47, \mathrm{XXY}$ zygote, suggesting loss of meiotic cells at the pachytene stage, which increases the risk of developing aneuploid sperm having a extra copy of the $\mathrm{Y}$ chromosome. These chromosomal imbalances are responsible for failure of the spermatogenic process; the small testis becomes a causative factor for NOA cases and clinically diagnosed as Klinefelter syndrome. Interestingly, we found a high 
frequency (40\%) of mosaicism with 46XY/47, XYY karyotype; which differs from the findings from South India, where a very low frequency $(0.5 \%)$ was reported (Saxena and Kumar, 2019). There are possible mechanisms by which these conditions might occur and there is precedence in other organisms for susceptibility the accident of non disjunction event either in one of the two meiotic divisions during gametogenesis in one of the parents. These genetic factors occur probably due to non - disjunction events during cellular differentiation at meiosis either in zygotene or pachytene stage, leading to an extra copy of the $\mathrm{Y}$ chromosome resulting in unhealthy sperm and mosaicism in post meiotic events.

Hence, between a positive correlation between Sox9 gene expression and genetic variations, i.e. either an extra copy of the $\mathrm{Y}$ chromosome or microdeletion of a euchromatic region ( $A Z F \mathrm{c}$ deletion), resulting in a non-disjunction event at meiotic II developing mosaicism 46,XY/47,XYY in karyotypes. The development of mosaicism with increasing number of $\mathrm{Y}$ chromosome has also been reported by Clementini et al. (2005) and Mierla et al. (2014).

The present study reveals significant findings, with more than $56 \%$ cases showing down-regulation of Sox9 gene expression due to frameshift mutation might have responsible for the removal of three amino acid glutamine -proline - alanine motif from $\mathrm{C}$ terminus in heterozygous condition suggesting that an extra dose of Sox 9 is required for normal functioning of testis (Foster et al., 1994; Wagner et al., 1994; Huang et al., 1999).

Sox 9 gene map on chromosome 17 , is an important member of Sox stem cell family and expressed in multiple tissue since it is testicular determinant and multiple copies has been reported during the formation of gonadal ridge and responsible for sex reversal cases i.e. 46,XY female and 46,XX Male (Georg et al., 2010). In the present study we have observe the higher expression of SRY+ve cases might be due to the microdeletion of Y-chromosome as also observed in the case of female sex reversal (Salehi et al., 2006). Sox9 gene is also associated with hypothalamic and pituitarygonadal access and effected phenotypes and varies spermatogenic dysfunction leading to gonadal dysgenesis and development of sex reversal cases besides initiation of congenital anomalies such as absence of vas deferens premature ovarian failure has also been reported by (Jedidi et al., 2018).

In Human and mice, the Sox9 gene (stem cell) expression is essential for normal function of Sertoli cell differentiation (Foster et al. 1994; Chaboissier et al. 2004) and mutation leads to affected in SRY expression and triggering abnormal sexual differentiation. Present study based on genetic data, where more than $56 \%$ cases of NOA shows down regulation of Sox9 gene expression indicating either loss of precursors of Sertoli cells or loss of cell - population inside the seminiferous tubules during spermatogenesis. Although, the upregulation of Sox9 gene has also been reported by Lan et al. (2013). However, the mechanism by which SRY action affecting Sox9 stem cell gene expression in abnormal sexual development of gonad leading to infertility in human is not yet understood. Further, present findings indicate role of Sox9 in the cases of NOA as compared to controls in the population of Bihar region, 
however, further large scale studies needs to be performed in different groups to identify its wider association with male infertility in different ethnic groups.

\section{CONCLUSIONS}

Sox9 is expressed in various kind of tissue during early embryogenesis, lineages commitment and stem cell maintenance. SRY belong to a high mobility group (HMG)-box DNA binding motif of the Sox family of transcription factors. We found a significant positive correlation of Sox9 gene expression (copy number variation) with SRY, similar to the microdeletion of $\mathrm{Y}$-chromosome and mosaicism (46,XY/47,XYY). Our hypothesis is based on the above genetic findings to explore the etiopathology of infertility - firstly, SRY expression is modulated either by Sox9 gene or mutation of the AZFc locus or due to mosaicism leading to a non-disjunction event at meiosis II, either alone or in synergistic manner as predicted in Figure 2. Secondly, the increased mosaicism suggests a extra copy of Y-chromosome, which may be due to a non-disjunction event with an extra dose of heterochromatin causing disequilibrium between euchromatin and heterochromatin in the recipient proliferating germ cells. Thirdly we have to find "causative factors" responsible for unequal cell-division during spermatogenesis, and lastly a possible interaction between the sex-chromosome genes and their linkage with autosomes for normal functioning of the events during spermatogenesis. Sox 9 acts as transcription factor of stem cells and in the future could be used as a "biological marker" as a source of regenerative medicine to resolve the problem of infertility. Furthermore, the characterization of Sox9 gene mutation should be performed in other laboratories to increase the population size involving different ethnic groups to make the study more applicable.

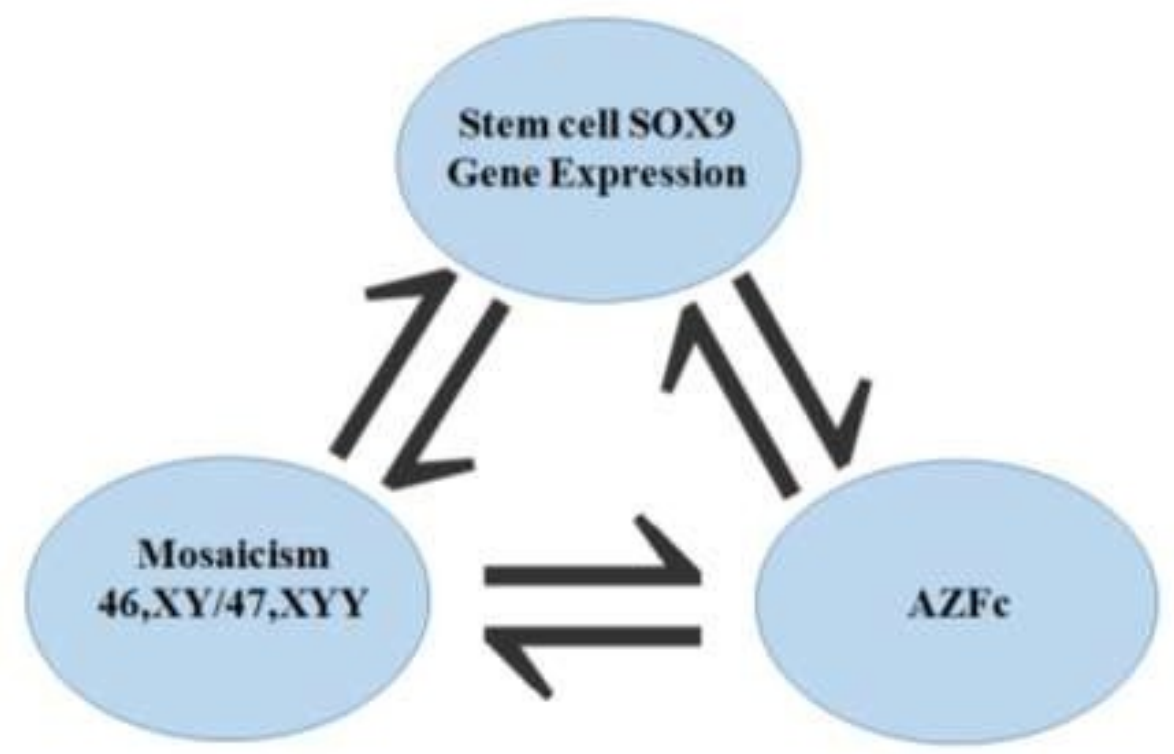

Figure 2. Hypothesis showing the etiopathology of genetic interaction between Stem cell Sox 9 gene, mosaicism and deletion of AZFc region either alone or in a synergistic manner in the cases of infertility. 


\section{ACKNOWLEDGMENTS}

AKS thankfully acknowledges our Director, AIIMS Patna, for valuable suggestions, and financial support provided by the Department of Biotechnology (Govt. India) No.BT/PR14671/MED/12/487/2010) to carry out this research work.

\section{CONFLICTS OF INTEREST}

The authors declare no conflict of interest.

\section{AUTHORS CONTRIBUTIONS}

AKS, A, RK, AK, CKS and MT are responsible for genetics analysis and development of the manuscript, MA made the clinical diagnosis of the patients.

\section{REFERENCES}

Athalye AS, Madon PF, Naik NJ, Naik DJ, et al. (2004). A Study of Y Chromosome Microdeletions in Infertile Indian Males. Int. J. Hum. Genet. 4: 179-85.

Berta P, Hawkins JR, Sinclair AH, Taylor A, et al. (1990). Genetic evidence equating SRY and the testis- determining factor. Nature. 348: 448-50.

Chaboissier MC, Kobayashi A, Vidal VI, Lützkendorf S, et al. (2004). Functional analysis of Sox8 and Sox9 during sex determination in the mouse. Development. 131: 1891-901.

Clementini E, Palka C and Iezzi I (2005). Prevalence of chromosomal abnormalities in 2078 infertile couples referred for assisted reproductive techniques. Hum. Reprod. 20: 437-442.

de la Chapelle A, Hastbacka J, Korhonen T and Maenpa A (1990). The etiology of XX sex reversal. Reprod. Nutr. Dev. (Suppl. 1). 39: 49

De Santa Barbara P, Bonneaud N, Boizet B, Desclozeaux M, et al. (1998). Direct interaction of SRY-related protein SOX9 and steroidogenic factor 1 regulates transcription of the human anti-Müllerian hormone gene. Mol. Cell. Biol. 18: 6653-65.

Foresta C, Moro E and Ferlin A (2001) Y chromosome microdeletions and alterations of spermatogenesis. Endocr. Rev. 22: 226-39.

Foster JW (1996). Mutations in SOX9 cause both autosomal sex reversal and campomelic dysplasia. Acta. Paediatr. Jpn. 38: 405-11.

Foster JW, Dominguez-Steglich MA, Guioli S, Kowk G, et al. (1994). Campomelic dysplasia and autosomal sex reversal caused by mutations in an SRY-related gene. Nature. 372: 525-30.

Goncalves C, Cunha M, Rocha E, Fernandes S, et al. (2017). Y-chromosome microdeletions in nonobstructive azoospermia and severe oligozoospermia. Asian J. Androl. 9: 338-45.

Grosschedi R, Giese K and Pagel J (1994). HMG domains protein: architectural elements in the assembly of nucleoprotein structure. Trends Genet. 10: 94-100.

Hsiao HP, Tsai LP, Chao MC, Tseng HI, et al. (2006). Novel SOX9 gene mutation in campomelic dysplasia with autosomal sex reversal. J. Formos. Med. Assoc. 105: 1013-6.

Huang B, Wang S, Ning Y, Lamb AN, et al. (1999). Autosomal XX sex reversal caused by duplication of SOX9. Am. J. Med. Genet. 87: 349-53.

Imataka G and Arisaka O (2012). Chromosome analysis using spectral karyotyping (SKY). Cell Biochem. Biophys. 62: $13-7$.

Jedidi I, Ouchari M and Yin Q (2018). Autosomal single-gene disorders involved in human infertility. Saudi J. Biol. Sci. 25: 881-887.

Jordan BK, Mohammed M, Ching ST, Delot E, et al. (2001). Up-regulation of WNT4 signaling and dosage-sensitive sex reversal in humans. Am. J. Hum. Genet. 68: 1102-9.

Koopman P, Gubbay J, Vivian N, Goodfellow P, et al. (1991). Male development of chromosomally female mice transgenic for Sry. Nature. 351: 117-21.

Kwok C, Weller PA, Guioli S, Foster JW, et al. (1995). Mutations in SOX9, the gene responsible for Campomelic dysplasia and autosomal sex reversal. Am. J. Hum. Genet. 57: 1028-36. 
Laan M (2019). Systematic review of the monogenetic causes of male infertility: the first step towards diagnostic gene panels in the andrology clinic. Hum. Reprod. 34: 783-85.

Lan K, Chen Y, Chang C, Chang Y, et al. (2013). Up-Regulation of SOX9 in Sertoli Cells from Testiculopathic Patients Accounts for Increasing Anti-Mullerian Hormone Expression via Impaired Androgen Receptor Signaling. PLoS One. 8(10): e76303.

Mierla D, Jardan D and Stoian V (2014). Chromosomal abnormality in men with impaired spermatogenesis. Int. J. Fertil. Steril. 8: 35-42.

Mol BW, Tjon-Kon-Fat R, Kamphuis E and van Wely M (2018). Unexplained infertility: Is it over-diagnosed and overtreated? Best Pract. Res. Clin. Obstet. Gynaecol. 53: 20-9.

Morais da Silva S, Hacker A, Harley V, Goodfellow P, et al. (1996). Sox9 expression during gonadal development implies a conserved role for the gene in testis differentiation in mammals and birds. Nat. Genet. 14: 62-8.

Robinson DO and Jacobs PA (1999). The origin of the extra Y chromosome in males with a 47, XYY karyotype. Hum. Mol. Genet. 8: 2205-9.

Ross JL, Roeltgen DP and Kushner H (2012). Behavioural and social phenotypes in boys with 47,XYY syndrome or 47,XXY Klinefelter syndrome. Pediatrics. 129: 769-78.

Salehi LB, Scarciolla O, Vanni GF, Nardone AM, et al. (2006). Identification of a novel mutation in the SRY gene in a 46, XY female patient. Eur. J. Med. Genet. 49: 494-498.

Saxena AK and Kumar A (2019). Microdeletion of the AZFc locus with high frequency of mosaicism 46,XY/47XYY in cases of non obstructive azoospermia in eastern population of India. Genet. Mol. Res. 18: gmr18349.

Sudbeck P, Schmitz ML, Baeuerle PA and Scherer G (1996). Sex reversal by loss of the C-terminal transactivation domain of human SOX9. Nat. Genet.13: 230-2.

Wagner T, Wirth J, Meyer J, Zabel B, et al. (1994). Autosomal sex reversal and campomelic dysplasia are caused by mutations in and around the SRY-related gene SOX9. Cell. 79: 1111-1120. 